\title{
Opportunism of plant seeds
}

\section{from Peter D. Moore}

THE germination of many types of seed can be triggered by various external, physical stimuli, such as temperature, water availability and light. Logically it would seem that such response mechanisms have developed as a consequence of a selective advantage gained by the plants whose development has previously been constrained in this way. Dormancy thus prevents the plant from germinating and expending its reserve at an inopportune moment, that is, one in which its chances of long-term survival are small.

The germination strategies of plants are therefore closely linked to the ecological problems presented by their particular habitat. Many weed species occupying unpredictable habitats, in which frequent catastrophe is an inevitable component of life, rely strongly upon the maintenance of a reservoir of dormant seeds in the soil to ensure survival of the holocaust. In such species a simple technique for dormancy maintenance is the linkage of dormancy breakage with exposure to light. Species which grow in dense grassland habitats would be at a great disadvantage if dormancy were maintained at low light intensity, for at ground level they may rarely experience anything else. The seeds of such species usually germinate in the dark. Species of woodland clearings depend on the death of a canopy tree or some other disturbance to open the leaf cover and provide an opportunity for growth. It might be supposed that such species would be at an advantage if their germination were finely tuned to the changes in spectral quality of light associated with a reduction in canopy. This is speculation, but it would make sound ecological and evolutionary sense.

Cresswell and Grime (see p.583 of this issue of Nature) point out an interesting correlation between the light demands of seeds and the environment within which they mature in the fruit. Seeds developing within tissues which are photosynthetic are shielded by these green layers and subsequently require a light stimulus for germination. Seeds which are exposed to full light before their final maturation and drying are capable of germinating without light.

Cresswell and Grime propose that species of unpredictable habitats which

Peter D. Moore is in the Department of Plant Sciences, University of London King's College. gain advantage by maintaining a dormant population of seeds in the soil, retain chlorophyllous tissues around their maturing seeds, thus producing a light requirement. It is even possible that some species whose seeds do not become incorporated in the soil seed bank may retain a green cover over maturing seed and thus induce a light requirement; such species may require the full light of an opening in the canopy to trigger germination.

Obviously, light is just one of many factors in the environment which influence germination and it is not always the overriding one. However, the experiments of Cresswell and Grime do suggest that the morphology and phenology of the inflorescence, flower and fruit can have a direct influence upon the subsequent germination requirements of the seed. This leads to the interesting possibility that ecotypic development within certain species, providing adaptation to a variety of habitats, could relate to such a minor modification as the chlorophyll content of structures investing the seed. It will be of value to look for such modifications among those plants which are capable of survival in both stable and unstable environments. kimberlites, however, persists. Elsewhere in the world the formation of kimberlites seems to require two factors - an Archaean-type upper mantle and a later addition of volatiles to it. In South America, Archaean areas are present, but they are mostly well away from sources of volatiles, such as later subduction zone activity. Both factors may be present to the north of the Sierra de la Ventana mountains, suggesting the possibility of kimberlites in southern Brazil and Uruguay, and the repetitive subduction along the Andean chain during the past billion years may also provide a volatile source, although Archaean upper mantle materials appear to be absent along this border.

Diamonds are a component of another intriguing feature of the South American Shield - the Roraima Formation - which forms the isolated mountain tops that were the locus for Conan Doyle's 'Lost World'. The basal conglomerates of this Precambrian sedimentary sequence are generally diamondiferous, and sedimentological studies (Gosh, Venezuela) show very clearly that the entire sequence came from the east. But what is the source of these sediments and where did the diamonds come from? The total original volume must have been at least 1 million $\mathrm{km}^{3}$. The age of the basement on which they lie is different in different areas and it is generally thought that the base of the Roraima itself is strongly diachronous. There are major differences when the sediments are traced laterally, but the scale of this deposit makes such variations inevitable. The puzzle is why the similarities should persist over 1 million $\mathrm{km}^{2}$. Sedimentological evidence clearly rules out the suggestion by Gaudett (New Hampshire) that local Venezuelan sources were of major importance. Gaudett and Olszweski demonstrated a consistent migration in the age of the formation of the basement rocks of southern Venezuela. Strontium isotopes showed that these Proterozoic granites and gneisses had little continental contamination, but their age decreased from $\sim 1,850 \mathrm{Myr}$ in the northeast to 1,550 Myr in the south-west. They suggested that this indicated a gradual migration of subduction activity up to a final suture zone close to the VenezuelanColombian border. What was important about Gaudett's study was that essentially similar techniques of whole-rock and zircon analyses were used. Many problems in understanding the geological evolution of South America arise from the wide variety of techniques that have been applied, each of which often represents the closure of a different geochemical system. Palaeomagnetic results, for example, from this and other Precambrian terrains, often assume that the radiometric age, irrespective of the method, represents the age of the magnetization. This may be true for some $\mathrm{K}-\mathrm{Ar}$ methods, but will generally not be the case for other techniques.

This radiometric dating problem is particularly important, on a world scale, in any attempt to understand the change from Archaean to Proterozoic tectonic conditions. There seems to be good evidence from virtually all other shield areas that Archaean tectonic conditions ceased between 2.5 and 2.7 billion years ago (Moorbath Phil. Trans. R. Soc. A 288; 401, 1978). In northern Venezuela, the Imataca Province has an age of 3.1-3.3 billion years, but the oldest age, so far, from the Guyana Shield is 2.2-2.1 billion years (Gibbs, thesis, Harvard University, 1979) - indicating the persistence of 'Archaean' greenstone formation for some 500-600 Myr longer that in the rest of the world. Unless these dates have been significantly reset, they clearly require drastic modifications to be made to fit tectonic models that involve a world-wide change from Archaean- to Proterozoic-type tectonics over a period of some $200 \mathrm{Myr}$. Such critical problems can only be resolved by further work. It is unlikely that the next meeting (Brazil 1984) will provide all the answers, but the First Amazonian Symposium has certainly set the scene within which further work can be more effectively planned. 